\title{
Assessment of cost drivers and cost variation for lumbar interbody fusion procedures using the Value Driven Outcomes database
}

\author{
Spencer Twitchell, BS, Michael Karsy, MD, PhD, MSc, Jared Reese, BS, Jian Guan, MD, \\ William T. Couldwell, MD, PhD, Andrew Dailey, MD, and Erica F. Bisson, MD, MPH \\ Department of Neurosurgery, Clinical Neurosciences Center, University of Utah, Salt Lake City, Utah
}

\begin{abstract}
OBJECTIVE Efforts to examine the value of care-combining both costs and quality-are gaining importance in the current health care climate. This thrust is particularly evident in treating common spinal disease where both incidences and costs are generally high and practice patterns are variable. It is often challenging to obtain direct surgical costs for these analyses, which hinders the understanding of cost drivers and cost variation. Using a novel tool, the authors sought to understand the costs of posterior lumbar arthrodesis with interbody devices.
\end{abstract}

METHODS The Value Driven Outcomes (VDO) database at the University of Utah was used to evaluate the care of patients who underwent open or minimally invasive surgery (MIS), 1- and 2-level lumbar spine fusion (Current Procedural Terminology code 22263). Patients treated from January 2012 through June 2017 were included.

RESULTS A total of 276 patients (mean age $58.9 \pm 12.4$ years) were identified; $46.7 \%$ of patients were men. Most patients $(82.2 \%)$ underwent 1 -level fusion. Thirteen patients (4.7\%) had major complications and $11(4.1 \%)$ had minor complications. MIS ( $\beta=0.16, p=0.002)$, length of stay $(\beta=0.47, p=0.0001)$, and number of operated levels $(\beta=0.37$, $p=0.0001)$ predicted costs in a multivariable analysis. Supplies and implants $(55 \%)$ and facility cost $(36 \%)$ accounted for most of the expenditure. Other costs included pharmacy $(7 \%)$, laboratory (1\%), and imaging (1\%).

CONCLUSIONS These results provide direct cost accounting for lumbar fusion procedures using the VDO database. Efforts to improve the value of lumbar surgery should focus on high cost areas, i.e., facility and supplies/implant. https://thejns.org/doi/abs/10.3171/2018.1.FOCUS17724

KEYWORDS cost-effectiveness; spine surgery; lumbar fusion; value-driven outcome; cost variation; minimally invasive; MIS

$\mathrm{O}$ NGOING discussions about using patient registries to improve understanding of disease subtypes and costs, along with new regulations from the US Centers for Medicare and Medicaid Services governing reimbursement strategies, have emphasized the importance of cost reduction and quality improvement in health care. To address these issues, the University of Utah created the Value Driven Outcomes (VDO) database to analyze direct cost, evaluate cost drivers, and identify opportunities for improvement. ${ }^{10,11,13}$ The advantage of the VDO database is the ability to evaluate direct care costs, which have otherwise been obscured by the complexity of the modern health care supply chain and reimbursement mechanisms. This is in contrast to most other studies evaluating health care cost, which instead have evaluated charges or price.

Treatment of degenerative spine conditions costs more

ABBREVIATIONS ASA = American Society of Anesthesiologists; MIS = minimally invasive surgery; VDO = Value Driven Outcomes

SUBMITTED November 29, 2017. ACCEPTED January 15, 2018.

INCLUDE WHEN CITING DOI: 10.3171/2018.1.FOCUS17724. 
than $\$ 85$ billion in 2006, and the costs have steadily increased. ${ }^{17}$ Instrumented lumbar spine surgery was shown to account for $\$ 12.8$ billion in 2001 in estimated overall US health care expenditures. ${ }^{6,24}$ Thus, despite the positive impact of lumbar fusion on patient-reported quality-of-life metrics, $3,8,23,25$ the value of lumbar spine surgery for virtually all indications has come under considerable criticism. The VDO database can be applied in cost-effectiveness analysis to calculate the value of treatments in neurosurgery. The goal of this study was to evaluate specific cost drivers of 1- and 2-level elective procedures for lumbar spine posterolateral fusion with interbody devices.

\section{Methods \\ Patient Inclusion}

After institutional review board approval was granted with a waiver of consent, the VDO database and a crossreferenced electronic medical record were utilized to identify cases in which 1- or 2-level elective combined posterolateral and interbody lumbar fusion were performed. A search by Current Procedural Terminology code 22263 (posterior or posterolateral arthrodesis, posterior interbody lumbar fusion) was performed for the period from January 2012 through June 2017. Only patients aged 18 years or older who underwent elective procedures for the treatment of degenerative spondylosis or spondylolisthesis with instability were included. Single- and 2-level interbody devices were included. A manual chart review was performed to verify surgery site and number of levels.

\section{Surgical Procedures}

The patients were primarily treated using either open surgery or minimally invasive surgery (MIS) approaches. Open procedures involved a traditional midline approach with laminectomy, foraminotomy, and medial facetectomy followed by disc removal, endplate preparation, and placement of an interbody cage. Polyetheretherketone cages were used almost exclusively at our center, and bone morphogenetic protein was not routinely used. Pedicle screws and rod constructs were used in all cases. Intraoperative navigation was also commonly used for instrumentation. The MIS procedure involved a midline incision for frame placement and 2 lateral incisions for instrumentation. An expandable retractor system was used for bone work (Versa-Trac Retractor System, Becton Dickinson) and interbody grafting on one side, whereas sextant-based, percutaneous screw placement (CD Horizon Sextant, Medtronic) was used on the other side.

\section{Analysis}

Patient demographic variables and surgical data were abstracted from the medical records for each patient. The American Society of Anesthesiologists (ASA) physical status classification system was used to assess patient status before surgery. Cases were recorded as either open or MIS approaches, and complications were delineated into major and minor categories. Major complications were deep wound infection or sepsis requiring surgical treatment, thrombosis (stroke, pulmonary embolism, or deep vein thrombosis), and hardware revision. Minor compli- cations involved intraoperative or postoperative medical management only and included superficial infection, dural tear, and ileus. Patient discharge destination was noted.

The VDO database is a novel resource that generates direct costs in lieu of patient/insurer charges, and its methodology has been previously reported..$^{10,11,13}$ Costs are formulated by calculating instrumentation and pharmaceutical purchase pricing. Facility and radiology costs are determined by the number of minutes patients spend in individual units or the time required for radiological studies. Total cost and subcategory costs, including pharmacy, imaging, supplies and implants, laboratory, and facility costs were analyzed. Subcategory cost is reported as a percentage of total cost, and actual dollar amounts are not reported as per agreement with the University of Utah. Instead, the mean percentage of total cost was calculated. For the entire patient cohort, costs were totaled and the fraction of total cost contribution for each patient was determined. The mean percentage of total costs may not total $100 \%$. For subcategory cost contribution, the subcategory cost for each patient was divided by the total. For these calculations, percentages will equal $100 \%$.

Continuous variables are reported as means and standard deviations and were analyzed by t-test. Noncontinuous variables were analyzed using the chi-square test. A multivariable linear regression was used to correlate factors with cost. IBM SPSS (version 20.0, IBM Corp.) was used for statistical analysis, with $\mathrm{p}<0.05$ considered significant.

\section{Results}

A total of 276 patients aged 18 years or older underwent 1- or 2-level elective lumbar posterolateral fusion with interbody devices from January 2012 to June 2017 (Table 1). The mean age of the patient population was $58.9 \pm 12.4$ years, and 129 (46.7\%) patients were men. Of the 276 patients, $227(82.2 \%)$ underwent 1-level procedures, and 49 (17.8\%) underwent 2-level procedures. Fourteen patients (5.1\%) were healthy (ASA class I), $176(63.8 \%)$ had mild systemic disease (ASA class II), 75 (27.2\%) had severe systemic disease (ASA class III), and $2(0.7 \%)$ had incapacitating systemic disease (ASA class IV). The mean hospital length of stay was $4.5 \pm 1.6$ days. One hundred ninety-four patients $(70.3 \%)$ went home without additional services from the hospital, 39 (14.1\%) were discharged with home health assistance, 19 each went to a skilled nursing facility and an acute rehabilitation facility (6.9\%), and 5 were discharged back to prison (1.8\%).

We compared open and minimally invasive lumbar interbody fusion procedures (Table 1). Of the 276 patients, $188(68.1 \%)$ underwent an open procedure, and $88(31.9 \%)$ underwent an MIS procedure. Patients in the MIS cohort were older $(p<0.0001)$, more likely to be female $(p=0.02)$, and stayed longer in the hospital $(\mathrm{p}<0.0001)$. The rate of complications $(p=0.45)$, ASA class $(p=0.79)$, number of surgical levels $(\mathrm{p}=0.64)$, and discharge disposition $(\mathrm{p}=$ 0.55 ) between the procedures were not significantly different $(\mathrm{p}=0.45)$.

Thirteen patients (4.7\%) had major complications, and $11(4.1 \%)$ had minor complications. Major complications included deep infection or sepsis $(3 ; 1.1 \%)$, thrombosis $(6$; 
TABLE 1. Demographic and clinical characteristics of all patients, and a comparison of open and MIS lumbar fusions

\begin{tabular}{|c|c|c|c|c|}
\hline Variable & $\begin{array}{c}\text { Total }(n= \\
276)\end{array}$ & $\begin{array}{c}\text { Open } \\
\text { Procedure } \\
(n=188)\end{array}$ & $\begin{array}{c}\text { MIS } \\
\text { Procedure } \\
(n=88)\end{array}$ & $p$ Value \\
\hline Mean age in yrs & $58.9 \pm 12.4$ & $57.1 \pm 13.1$ & $62.8 \pm 9.7$ & $<0.0001$ \\
\hline Male sex & $129(46.7)$ & $97(51.6)$ & $32(36.4)$ & 0.02 \\
\hline $\begin{array}{l}\text { Mean length of stay } \\
\text { in days }\end{array}$ & $4.5 \pm 1.6$ & $4.2 \pm 1.8$ & $5.1 \pm 1.1$ & $<0.0001$ \\
\hline Complication & $24(8.7)$ & $18(9.6)$ & $6(6.8)$ & 0.45 \\
\hline ASA class & & & & 0.79 \\
\hline I & $14(5.1)$ & $10(5.3)$ & $4(4.5)$ & \\
\hline II & $176(63.8)$ & $119(63.3)$ & $57(64.8)$ & \\
\hline III & $75(27.2)$ & $51(27.1)$ & $24(27.3)$ & \\
\hline IV & $2(0.7)$ & $2(1.1)$ & $0(0)$ & \\
\hline No. of surgical levels & & & & 0.64 \\
\hline 1 & $227(82.2)$ & $156(83.0)$ & $71(80.7)$ & \\
\hline 2 & $49(17.8)$ & $32(17.0)$ & $17(19.3)$ & \\
\hline Discharge disposition & & & & 0.55 \\
\hline Home & $194(70.3)$ & $130(69.1)$ & $64(72.7)$ & \\
\hline Home health & 39 (14.1) & $29(15.4)$ & $10(11.4)$ & \\
\hline $\begin{array}{l}\text { Skilled nursing } \\
\text { facility }\end{array}$ & $19(6.9)$ & $13(6.9)$ & $6(6.8)$ & \\
\hline Acute rehabilitation & $19(6.9)$ & $11(5.9)$ & $8(9.1)$ & \\
\hline Prison & $5(1.8)$ & $5(2.7)$ & $0(0.0)$ & \\
\hline
\end{tabular}

Values are presented as the number of patients (\%) unless stated otherwise. Mean values are shown as $\pm S D$. Boldface type indicates statistical significance.

$2.2 \%)$, and hardware revision $(4 ; 1.4 \%)$. Superficial wound or urinary tract infection $(9 ; 3.3 \%)$, dural tears $(1 ; 0.4 \%)$, and ileus $(1 ; 0.4 \%)$ were coded as minor complications (Table 2).

The percentage of total cost for each patient was calculated and averaged for open versus MIS cases. There was a significantly higher mean cost for MIS cases $(0.35 \% \pm$ $0.1 \%$ vs $0.40 \% \pm 0.07 \%, p=0.0001)$. On average, MIS cases were 1.14 times more expensive than open procedures. Subtotaled costs suggested that supplies and implants had a slightly higher cost for MIS cases (Fig. 1A) than for the other cost categories (i.e., facility, pharmacy, imaging, and laboratory).

\section{TABLE 2. Patient complications after lumbar fusion}

\begin{tabular}{lc}
\hline \multicolumn{1}{c}{ Complication Type } & Frequency $(\%)$ \\
\hline Major, $n=13$ & \\
\hline Infection (deep wound/sepsis) & $3(1.1)$ \\
\hline Thrombosis* & $6(2.2)$ \\
\hline Hardware revision & $4(1.4)$ \\
\hline Minor, $n=11$ & $9(3.3)$ \\
\hline Infection (superficial wound/urinary tract infection) & $1(0.4)$ \\
\hline Dural tears & $1(0.4)$ \\
\hline lleus
\end{tabular}

* Includes stroke, pulmonary embolism, and deep vein thrombosis.


FIG. 1. Cost analysis of lumbar fusions by cost category and length of stay. A: Subtotal cost categories for open and MIS procedures are shown. Each cost is a percentage of the total cost for this group of patients. B: A grouped scatterplot showing the relationship among costs, number of levels operated, and length of stay. C: Pie chart representing the distribution of total cost by subcategory: facility (36\%), supplies and implants (55\%), pharmacy (7\%), laboratory $(1 \%)$, and imaging (1\%). 
TABLE 3. Multivariate valuation of factors correlating with cost

\begin{tabular}{lccc}
\hline \multicolumn{1}{c}{ Variable } & Standardized $\beta$ & $95 \% \mathrm{Cl}$ & $p$ Value \\
\hline Age & -0.03 & -0.001 to 0.0001 & 0.56 \\
\hline Sex & 0.1 & 0.001 to 0.03 & $\mathbf{0 . 0 4}$ \\
\hline Length of stay & 0.47 & 0.02 to 0.03 & $<0.0001$ \\
\hline Complication & -0.064 & -0.05 to 0.009 & 0.18 \\
\hline ASA class & -0.001 & -0.02 to 0.02 & 0.99 \\
\hline No. of levels & 0.37 & 0.06 to 0.1 & $<0.0001$ \\
\hline Disposition & 0.062 & -0.003 to 0.01 & 0.20 \\
\hline MIS & 0.16 & 0.01 to 0.05 & $\mathbf{0 . 0 0 2}$ \\
\hline
\end{tabular}

Boldface type indicates statistical significance.

In a multivariable analysis of factors potentially affecting cost, undergoing an MIS approach (multivariate $\beta=$ $0.16, p=0.002$ ), having a longer hospital stay (multivariate $\beta=0.47, p=0.0001$ ), and requiring a greater number of operated levels (multivariate $\beta=0.37, p=0.0001$ ) were all independent predictors of higher cost, with length of stay as the most significant contributor (Table 3). A scatterplot of the length of stay and percentage of the total cost for 1and 2-level procedures demonstrated a direct correlation between length of stay and cost (Fig. 1B).

The distribution of total cost included supplies and implants $(55 \%)$, facility (36\%), pharmacy $(7 \%)$, laboratory (1\%), and imaging (1\%; Fig. 1C). Supplies and implants combined with facility utilization governed $91 \%$ of the total cost. The added cost associated with MIS cases (on average 1.13 times as much as open cases) was primarily mediated by facility cost and supplies/implants.

\section{Discussion}

The results of this study highlight the cost distribution for patients undergoing 1- or 2-level elective posterolateral and interbody lumbar fusions for degenerative conditions. The results suggest that facility as well as supply and implant costs are the most influential components in this surgical population. In fact, supplies and implants accounted for $55 \%$ of total direct costs, followed by $36 \%$ for facility fees, together totaling $91 \%$ of the total cost of care for this patient group. Significant variables most affecting the cost in a multivariable analysis included the selection of MIS over an open technique, hospital length of stay, and the number of operated levels. Not surprisingly, a longer length of stay and greater number of surgical levels showed a clear correlation with total cost. Unexpectedly, utilization of an MIS approach resulted in a higher cost than open surgical fusion, even when controlling for age, patient surgical risk score, number of levels, and length of stay.

\section{Cost-Effectiveness Research in Spine Surgery}

Identification of factors affecting surgical spine care is important for identifying methods for cost reduction. Various approaches in studying cost-effectiveness in lumbar spine surgery have previously been performed for specific patient populations, such as patients with spondylolisthesis and those with scoliosis and when surgical approaches like MIS are used..$^{2,4,5,7,9,12,15,19-21}$ For example, Parker et al..$^{18}$ evaluated variables affecting cost of fusion and nonfusion spine surgeries using the National Neurosurgery Quality and Outcomes Database ( $\left.{ }^{2} \mathrm{QOD}\right)$. This study identified length of stay, number of admission diagnoses and procedures, hospital size and region, patient income, fusion surgery, acute renal failure, sex, and coagulopathy as common drivers of cost. A study by Emohare et al. ${ }^{1}$ suggested that use of vancomycin powder improved cost savings by reducing the infection rate associated with posterior spine surgeries. The authors evaluated a total of 303 patients undergoing instrumented and noninstrumented surgery, with 96 receiving vancomycin powder at the surgical site at a cost of \$12 (total cost for the cohort \$1152). No infection was observed in patients receiving vancomycin, whereas 7 patients experienced postsurgical infection in the nonvancomycin group, which had an additional \$573,898 in standard surgical costs. An interdisciplinary approach toward reduction of costs for spine surgery might allow for better selection of patients and cost savings. In a study by Viola et al., ${ }^{22} 112$ patients underwent conservative treatment and 218 were referred for surgical treatment. The total cost for the cohort decreased $158.5 \%$ because interdisciplinary discussion increased referral for conservative treatment.

Other identified surgical or postsurgical factors have been evaluated in an effort to identify ways to reduce patient cost. One study analyzed total costs of 1- and 2-level lumbar arthroplasties compared with circumferential lumbar fusion. ${ }^{14}$ This study showed significantly lower charges for single-level lumbar disc replacements versus fusions $(\$ 35,592$ vs $\$ 46,280, p=0.0018)$ and suggested that operating room charges $(\$ 12,000$ vs $\$ 18,950)$ had more influence than implant charges $(\$ 13,800$ vs $\$ 13,990)$ on total cost variability. These results, combined with our findings that supplies and implants and facility costs made up $91 \%$ of the costs of care, suggest that strategies containing costs of spine surgery should focus on these categories.

Of interest, we found that MIS had a higher cost than traditional open surgery. Although this difference was statistically significant, it was clinically small. The absolute increase in mean total for MIS versus open surgery was 4.7\%; this difference was almost entirely accounted for by increased supply and implant costs with MIS procedures in our study. Other studies have shown improved cost savings for MIS. A study by Lucio et al. ${ }^{16}$ showed a cost savings of an average of $\$ 2825.37$ for MIS posterior lumbar interbody fusion procedures compared with open procedures, a difference that was statistically significant. This finding suggests that MIS procedures can affect overall costs unexpectedly for certain patient groups.

\section{Novel Cost-Based Database}

The VDO database has been instrumental to our understanding of health care cost at the University of Utah. ${ }^{10,11,13}$ After the VDO system was implemented, hip replacement costs and hospital laboratory testing costs were reduced through quality improvement initiatives. ${ }^{13}$ The database can also track medical process changes. For example, earlier intervention in sepsis across the institution, recommended after VDO analysis, reduced the overall cost of 
the hospital encounter. Our previous analysis of cost drivers in the transsphenoidal resection of pituitary adenomas showed that facility costs, complex patient comorbidities, and patient complications were important factors in understanding overall cost. ${ }^{10}$ This work suggested that reduction of cost in an inpatient setting would need to focus on facility costs, reduced length of stay, and reduction of complications in order to make a meaningful impact. This current analysis of cost drivers in lumbar fusion procedures serves to further elucidate cost drivers in neurosurgical diseases and interventions. One of the potential next steps from this project could involve the further standardization of spine fusion care, implementation of a fast-track mobilization program, and other specific steps to reduce extraneous costs for procedures or materials. The use of a cost database in lumbar spine surgery might offer novel insights compared with traditional cost-effectiveness approaches, for example, that implants and supplies outweigh the impact of facility charges. We think a benefit of the VDO cost database is that it offers more accurate information as to true health care costs.

\section{Limitations}

One limitation of the study is in the use of a single center, where practice patterns may be more uniform. Such findings might not necessarily be generalizable to other centers. Furthermore, several efforts to contain costs are ongoing. In addition, the limited sample size for individual providers, as well as changing practice patterns over time, do not allow for easy identification of specific factors that may be addressable in containing spine care costs.

\section{Conclusions}

The results of this study demonstrate that supply and implant costs and facility utilization are important in governing the overall cost of 1- or 2-level elective lumbar fusion surgeries. Reduction of length of stay and price negotiation regarding instrumentation might be effective methods of controlling costs. This study is unique in that we used a cost-specific database to evaluate costs associated with 1- and 2-level elective lumbar fusion surgeries, resulting in distinct conclusions from previous charge-based study designs. Specific approaches toward improving efficient resource utilization and monitoring outcomes are likely to be important to reduce cost, yet maintain health care quality.

\section{References}

1. Emohare O, Ledonio CG, Hill BW, Davis RA, Polly DW Jr, Kang MM: Cost savings analysis of intrawound vancomycin powder in posterior spinal surgery. Spine J 14:2710-2715, 2014

2. Gandhoke GS, Shin HM, Chang YF, Tempel Z, Gerszten PC, Okonkwo DO, et al: A cost-effectiveness comparison between open transforaminal and minimally invasive lateral lumbar interbody fusions using the incremental cost-effectiveness ratio at 2-year follow-up. Neurosurgery 78:585595,2016

3. Ghogawala Z, Dziura J, Butler WE, Dai F, Terrin N, Magge $\mathrm{SN}$, et al: Laminectomy plus fusion versus laminectomy alone for lumbar spondylolisthesis. N Engl J Med 374:14241434,2016
4. Goldstein CL, Phillips FM, Rampersaud YR: Comparative effectiveness and economic evaluations of open versus minimally invasive posterior or transforaminal lumbar interbody fusion: a systematic review. Spine (Phila Pa 1976) 41 (Suppl 8):S74-S89, 2016

5. Gottschalk MB, Premkumar A, Sweeney K, Boden SD, Heller J, Yoon ST, et al: Posterolateral lumbar arthrodesis with and without interbody arthrodesis for L4-L5 degenerative spondylolisthesis: a comparative value analysis. Spine (Phila Pa 1976) 40:917-925, 2015

6. Goz V, Rane A, Abtahi AM, Lawrence BD, Brodke DS, Spiker WR: Geographic variations in the cost of spine surgery. Spine (Phila Pa 1976) 40:1380-1389, 2015

7. Hofstetter CP, Hofer AS, Wang MY: Economic impact of minimally invasive lumbar surgery. World J Orthop 6:190201,2015

8. Kaiser MG, Eck JC, Groff MW, Watters WC III, Dailey AT, Resnick DK, et al: Guideline update for the performance of fusion procedures for degenerative disease of the lumbar spine. Part 1: introduction and methodology. J Neurosurg Spine 21:2-6, 2014

9. Kaloostian PE, Gokaslan ZL: Evidence-based review of transforaminal lumbar interbody fusion: is minimally invasive better? World Neurosurg 82:65-67, 2014

10. Karsy M, Brock AA, Guan J, Bisson EF, Couldwell WT: Assessment of cost drivers in transsphenoidal approaches for resection of pituitary tumors using the value-driven outcome database. World Neurosurg 105:818-823, 2017

11. Kawamoto K, Martin CJ, Williams K, Tu MC, Park CG, Hunter C, et al: Value driven outcomes (VDO): a pragmatic, modular, and extensible software framework for understanding and improving health care costs and outcomes. J Am Med Inform Assoc 22:223-235, 2015

12. Khanna R, McDevitt JL, Abecassis ZA, Smith ZA, Koski TR, Fessler RG, et al: An outcome and cost analysis comparing single-level minimally invasive transforaminal lumbar interbody fusion using intraoperative fluoroscopy versus computed tomography-guided navigation. World Neurosurg 94:255-260, 2016

13. Lee VS, Kawamoto K, Hess R, Park C, Young J, Hunter C, et al: Implementation of a value-driven outcomes program to identify high variability in clinical costs and outcomes and association with reduced cost and improved quality. JAMA 316:1061-1072, 2016

14. Levin DA, Bendo JA, Quirno M, Errico T, Goldstein J, Spivak J: Comparative charge analysis of one- and two-level lumbar total disc arthroplasty versus circumferential lumbar fusion. Spine (Phila Pa 1976) 32:2905-2909, 2007

15. Lubelski D, Mihalovich KE, Skelly AC, Fehlings MG, Harrop JS, Mummaneni PV, et al: Is minimal access spine surgery more cost-effective than conventional spine surgery? Spine (Phila Pa 1976) 39 (22 Suppl 1):S65-S74, 2014

16. Lucio JC, Vanconia RB, Deluzio KJ, Lehmen JA, Rodgers JA, Rodgers W: Economics of less invasive spinal surgery: an analysis of hospital cost differences between open and minimally invasive instrumented spinal fusion procedures during the perioperative period. Risk Manag Healthc Policy 5:65-74, 2012

17. Martin BI, Deyo RA, Mirza SK, Turner JA, Comstock BA, Hollingworth W, et al: Expenditures and health status among adults with back and neck problems. JAMA 299:656-664, 2008

18. Parker SL, McGirt MJ, Bekelis K, Holland CM, Davies J, Devin CJ, et al: The National Neurosurgery Quality and Outcomes Database Qualified Clinical Data Registry: 2015 measure specifications and rationale. Neurosurg Focus 39(6): E4, 2015

19. Parker SL, Mendenhall SK, Shau DN, Zuckerman SL, Godil SS, Cheng JS, et al: Minimally invasive versus open transfo- 
raminal lumbar interbody fusion for degenerative spondylolisthesis: comparative effectiveness and cost-utility analysis. World Neurosurg 82:230-238, 2014

20. Uddin OM, Haque R, Sugrue PA, Ahmed YM, El Ahmadieh TY, Press JM, et al: Cost minimization in treatment of adult degenerative scoliosis. J Neurosurg Spine 23:798-806, 2015

21. Vertuani S, Nilsson J, Borgman B, Buseghin G, Leonard C, Assietti R, et al: A cost-effectiveness analysis of minimally invasive versus open surgery techniques for lumbar spinal fusion in Italy and the United Kingdom. Value Health 18:810-816, 2015

22. Viola DC, Lenza M, Almeida SL, Santos OF, Cendoroglo Neto M, Lottenberg CL, et al: Spine surgery cost reduction at a specialized treatment center. Einstein (Sao Paulo) 11:102107,2013

23. Weinstein JN, Lurie JD, Tosteson TD, Hanscom B, Tosteson AN, Blood EA, et al: Surgical versus nonsurgical treatment for lumbar degenerative spondylolisthesis. N Engl J Med 356:2257-2270, 2007

24. Weiss AJ, Elixhauser A, Andrews RM: Characteristics of Operating Room Procedures in U.S. Hospitals, 2011. Statistical Brief \#170. Rockville, MD: Agency for Healthcare Research and Quality, 2014 (https://hcup-us.ahrq.gov/ reports/statbriefs/sb170-Operating-Room-Procedures-UnitedStates-2011.jsp) [Accessed March 8, 2018]

25. Yagi M, Ames CP, Keefe M, Hosogane N, Smith JS, Shaffrey
CI, et al: A cost-effectiveness comparisons of adult spinal deformity surgery in the United States and Japan. Eur Spine J 27:678-684, 2018

\section{Disclosures}

Dr. Dailey: consultant for Zimmer Biomet and K2M; support of non-study-related clinical or research effort from K2M; and honoraria from AO North America. Dr. Bisson: direct stock ownership in nView.

\section{Author Contributions}

Conception and design: Bisson. Acquisition of data: Twitchell, Reese. Analysis and interpretation of data: Karsy. Drafting the article: Twitchell, Karsy, Reese. Critically revising the article: all authors. Reviewed submitted version of manuscript: Bisson, Karsy. Approved the final version of the manuscript on behalf of all authors: Bisson.

\section{Correspondence}

Erica F. Bisson: Clinical Neurosciences Center, University of Utah, Salt Lake City, UT. neuropub@hsc.utah.edu. 